07

\title{
Электронная структура металлических слоев в двухслойном квазидвумерном органическом металле (BETS) ${ }_{4} \mathrm{HgBr}_{4}\left(\mathrm{C}_{6} \mathrm{H}_{4} \mathrm{Cl}_{2}\right)$
}

\author{
() Р.Б. Любовский ${ }^{1,2}$, С.И. Песоцкий ${ }^{1,2, \text { Ф Е.И. Жиляева }}{ }^{1}$, А.М. Флакина ${ }^{1}$, Р.Н. Любовская ${ }^{1}$ \\ ${ }^{1}$ Институт проблем химической фризики РАН, Черноголовка, Московская обл., Россия \\ ${ }^{2}$ International Laboratory of High Magnetic Fields and Low Temperatures, Wroclaw, Poland \\ IE-mail: pesot@icp.ac.ru
}

Поступило в Редакцию 29 декабря 2018г.

В окончательной редакции 30 января 2019г.

Принято к публикации 1 фревраля 2019г.

Исследовано поведение осцилляций Шубникова-де Гааза в двухслойном органическом металле $(\mathrm{BETS})_{4} \mathrm{HgBr}_{4}\left(\mathrm{C}_{6} \mathrm{H}_{4} \mathrm{Cl}_{2}\right)$. Показано, что спектр осцилляций в этом соединении хорошо согласуется с теоретическими расчетами и качественно совпадает со спектром в изоструктурном металле $\left(\mathrm{ET}_{4} \mathrm{HgBr}_{4}\left(\mathrm{C}_{6} \mathrm{H}_{4} \mathrm{Cl}_{2}\right)\right.$. При этом частичное замещение атомов серы атомами селена в катионном слое сильно уменьшает величины циклотронных масс. Это уменьшение, скорее всего, вызвано ослаблением электрон-фононного взаимодействия.

DOI: 10.21883/PJTF.2019.08.47621.17667

Традиционные органические квазидвумерные металлы представляют собой катион-радикальные соли, синтезированные на основе молекулы ЕТ (бис(этилендитио)тетратиофульвален) и ее производных. В процессе синтеза формируются слоистые монокристаллические образцы, в которых катионные слои, состоящие из молекул ЕТ и обладающие благодаря значительному перекрытию атомных орбиталей серы металлической проводимостью вдоль слоя, чередуются с изолирующими анионными слоями [1-3]. Таким образом, в результате получается хорошо выраженный слоистый органический металл с анизотропией проводимости вдоль и перпендикулярно слоям порядка $10^{3}-10^{4}$. Одна из особенностей традиционных органических металлов заключается в том, что молекулярная и электронная структура катионных слоев в них одинакова или почти одинакова. Это приводит к единой поверхности Ферми (ПФ) внутри каждого слоя и общей ПФ для всей обратной решетки, имеющей форму цилиндра с осью, перпендикулярной металлическим слоям [1-3]. Сравнительно недавно синтезирован новый класс квазидвумерных органических металлов - так называемых двухслойных металлов [4,5]. В этих материалах электронная и молекулярная структура соседних катионных слоев различается, и свойства катионного слоя, в частности ПФ, транслируются через слой. В работе [5] приводятся исследования структуры и свойств двухслойного квазидвумерного органического металла $(\mathrm{ET})_{4} \mathrm{CoBr}_{4}\left(\mathrm{C}_{6} \mathrm{H}_{4} \mathrm{Cl}_{2}\right)$. Рентгеноструктурный анализ показал наличие в нем двух различных чередующихся катионных слоев. Детальный расчет зонной структуры позволил установить, что один из слоев с упаковкой молекул ЕТ $\alpha$-типа представляет собой диэлектрик с малой щелью, ширина которой не превосходит точности расчета. Другой слой является металлом с ПФ, представленной на вставке к рис. 1. Эта ПФ характерна для $\theta$-типа упаковки молекул ЕТ в катионном слое [1-3].
Анализ квантовых осцилляций в $(\mathrm{ET})_{4} \mathrm{CoBr}_{4}\left(\mathrm{C}_{6} \mathrm{H}_{4} \mathrm{Cl}_{2}\right)$ показал хорошее согласие частотного спектра осцилляций с теоретическими расчетами. Аналогичный результат был получен при исследовании осцилляций в изоструктурном комплексе $(\mathrm{ET})_{4} \mathrm{HgBr}_{4}\left(\mathrm{C}_{6} \mathrm{H}_{4} \mathrm{Cl}_{2}\right)$ [6]. $\mathrm{B}$ настоящей работе предлагаются результаты исследования осцилляций Шубникова-де Гааза (ШдГ) в изоструктурном двухслойном органическом металле (BETS $)_{4} \mathrm{HgBr}_{4}\left(\mathrm{C}_{6} \mathrm{H}_{4} \mathrm{Cl}_{2}\right)$. В этом соединении помимо изменения состава аниона часть атомов серы в молекуле ET заменена на атомы селена. Принимая во внимание то, что перекрытие орбиталей именно атомов серы обеспечивает металлическую проводимость в слоях ЕТ, можно ожидать заметные изменения проводящих свойств в BETS-комплексе даже при условии идентичности их кристаллических структур.

Исследование сопротивления в (BETS) ${ }_{4} \mathrm{HgBr}_{4}\left(\mathrm{C}_{6} \mathrm{H}_{4} \mathrm{Cl}_{2}\right)$ проводилось на монокристаллических образцах, имеющих форму неправильного параллелепипеда со средним размером $1.0 \times 0.4 \times 0.02 \mathrm{~mm}$, стандартным четырехконтактным методом на постоянном измерительном токе $1 \mu \mathrm{A}$, направленном перпендикулярно проводящим слоям. Магнитосопротивление изучалось при гелиевых температурах в полях до $14 \mathrm{~T}$, создаваемых сверхпроводящим магнитом. При необходимости измерительная вставка позволяла поворачивать образец как в азимутальной, так и в полярной плоскости, не извлекая его из магнита. На рис. 1 представлена зависимость сопротивления от температуры. Монотонный неметаллический ход сопротивления имеет место во всем интервале температур. При этом для сопротивления вдоль проводящих слоев характерно нормальное для металлов уменьшение сопротивления с уменьшением температуры [5]. Такое поведение радикально отличает исследованный материал от традиционных органических квазидвумерных металлов [3], но оно достаточно 


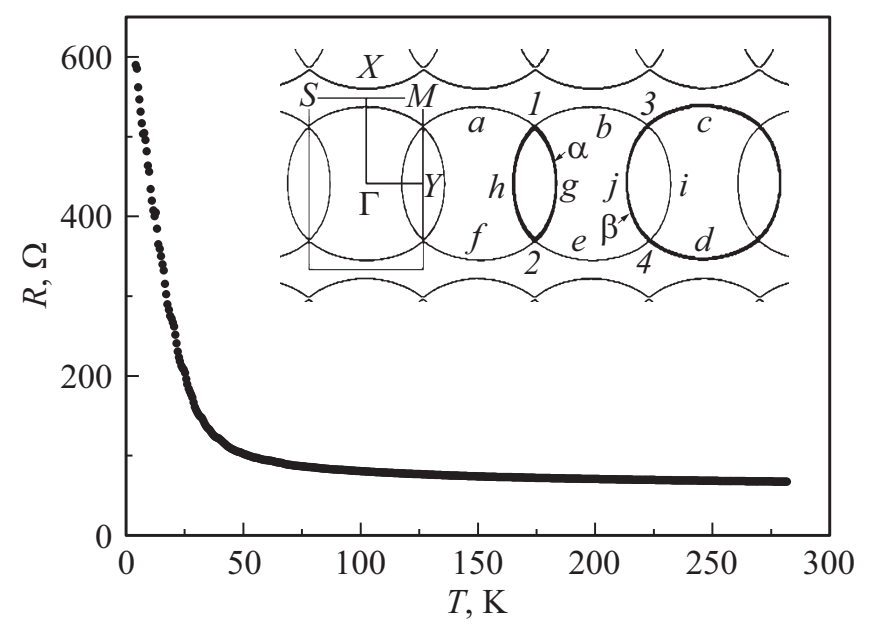

Рис. 1. Температурная зависимость межслоевого сопротивления в (BETS $)_{4} \mathrm{HgBr}_{4}\left(\mathrm{C}_{6} \mathrm{H}_{4} \mathrm{Cl}_{2}\right)$. На вставке - схематическое изображение поверхности Ферми металлического катионного слоя в $(\mathrm{ET})_{4} \mathrm{CoBr}_{4}\left(\mathrm{C}_{6} \mathrm{H}_{4} \mathrm{Cl}_{2}\right)$ [5]. Пояснение в тексте.

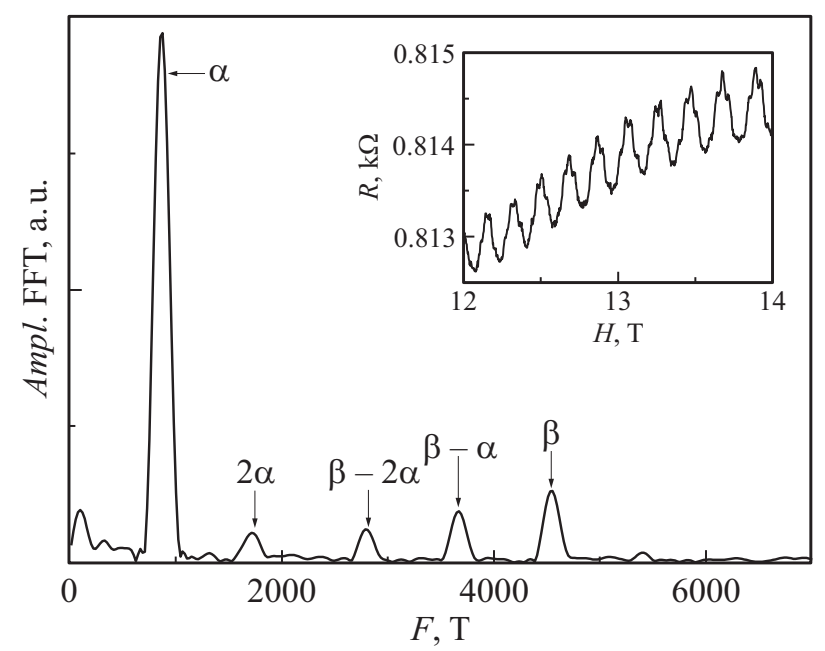

Рис. 2. Фурье-спектр осцилляций Шубникова-де Гааза в (BETS $)_{4} \mathrm{HgBr}_{4}\left(\mathrm{C}_{6} \mathrm{H}_{4} \mathrm{Cl}_{2}\right)$, представленных на вставке к рисунку. $T=1.5 \mathrm{~K}, \theta=0^{\circ}$.

часто встречается в двухслойных объектах [5] и при этом имеет простое объяснение. Неметаллический ход межслоевого сопротивления соответствует некогерентному переносу электронов, определяемому соотношением времен $\tau_{h}=\hbar / t \gg \tau_{c}$, где $\tau_{h}-$ время межслоевого перехода, $t$ - интеграл перехода, $\tau_{c}-$ время рассеяния электрона в слое, т.е. между переходами электрона на соседний металлический слой он многократно рассеивается в слое [1,3,7-9]. При идентичности кристаллических структур в ET- и BETS-металлах переход электрона с металлического слоя на соседний катионный слой исключается; следовательно, величина $t$ резко уменьшается, что обеспечивает устойчивый некогерентный межслоевой транспорт. Аналогичное поведение температурной зависимости сопротивления, соответствующее системе почти невзаимодействующих металлических слоев, наблюдалось и в изоструктурном комплексе $(\mathrm{ET})_{4} \mathrm{HgBr}_{4}\left(\mathrm{C}_{6} \mathrm{H}_{4} \mathrm{Cl}_{2}\right)$ [6].

На рис. 2 представлен фурье-спектр осцилляций ШдГ в (BETS $)_{4} \mathrm{HgBr}_{4}\left(\mathrm{C}_{6} \mathrm{H}_{4} \mathrm{Cl}_{2}\right)$. Пример таких осцилляций изображен на вставке к рис. 2. Спектр хорошо согласуется с теоретическими расчетами ПФ для соли $(\mathrm{ET})_{4} \mathrm{CoBr}_{4}\left(\mathrm{C}_{6} \mathrm{H}_{4} \mathrm{Cl}_{2}\right)$ (рис. 1) [5] и совпадает со спектром осцилляций, обнаруженным ранее в металле $(\mathrm{ET})_{4} \mathrm{HgBr}_{4}\left(\mathrm{C}_{6} \mathrm{H}_{4} \mathrm{Cl}_{2}\right)$ [6]. Величины всех частот осцилляций в квазидвумерных металлах в силу цилиндрического характера ПФ должны зависеть от полярного угла $\theta$ между направлением магнитного поля и нормалью к проводящим слоям по закону $F_{i}(\theta)=F_{i}(0) / \cos \theta$, где $i=\alpha, \beta, 2 \alpha, \ldots[1-3]$. Спектр содержит две фундаментальные частоты $F_{\alpha}\left(F_{\alpha}(0) \approx 875 \mathrm{~T}\right)$ и $F_{\beta}\left(F_{\beta}(0) \approx 4550 \mathrm{~T}\right)$, отвечающие $\alpha$ - и $\beta$-орбитам, охватывающим 19 и $100 \%$ площади первой зоны Бриллюэна соответственно. Циклотронные массы, связанные с этими частотами, вычислялись из температурных зависимостей амплитуды осцилляций. Величины амплитуды определялись исходя из фурье-спектров в интервале полей 12-14 Т. Каждая температура в процессе изменения поля стабилизировалась откачкой паров жидкого гелия. Значения циклотронной массы составляют $m_{\alpha}=(1.2 \pm 0.2) m_{0}$ и $m_{\beta}=(2.2 \pm 0.2) m_{0}$, где $m_{0}-$ масса свободного электрона. Существование $\alpha$ - и $\beta$-частот вызвано возникновением щели в точках $1-4$ пересечения исходной ПФ, составляющей 100\% зоны Бриллюэна (два электрона на элементарную ячейку), с границей этой зоны. В результате образуются замкнутая дырочная $\alpha$-орбита $(h \lg 2 h)$ и два листа открытой электронной орбиты $(\ldots a b c \ldots$ и . . def f . . ) (см. вставку на рис. 1). Магнитный пробой и переход электрона через щель с $\alpha$-орбиты на открытые участки формируют замкнутую $\beta$-орбиту.

Помимо фундаментальных частот спектр содержит комбинационные частоты $\mathrm{F}_{\beta-\alpha}(0) \approx 3670 \mathrm{~T}$ и $F_{\beta-2 \alpha}(0) \approx 2790 \mathrm{~T}$, для которых отсутствуют разрешенные замкнутые орбиты. Их появление, скорее всего, связано с эффектом квантовой интерференции $[10,11]$. Такое явление оказывается наиболее доступно для наблюдения в двумерных металлах благодаря цилиндрической форме ПФ [12]. В этом варианте частоте $F_{\beta-\alpha}$ соответствует интерферометр с траекториями abief и $a g f$, а частоте $F_{\beta-2 \alpha}-$ с траекториями abief и aghgf (см. вставку на рис. 1). Подтверждением этой версии может служить соотношение циклотронных масс, характерное для интерференционного процесса: $\quad m_{\beta-\alpha}=(1.1 \pm 0.2) m_{0} \sim m_{\beta}-m_{\alpha} \quad$ и $m_{\beta-2 \alpha}=(0 \pm 0.2) m_{0} \sim m_{\beta}-2 m_{\alpha}$.

Следует отметить, что циклотронные массы, связанные с замкнутыми орбитами, в (BETS $)_{4} \mathrm{HgBr}_{4}\left(\mathrm{C}_{6} \mathrm{H}_{4} \mathrm{Cl}_{2}\right)$ почти в 2 раза меньше аналогичных циклотронных масс в изоструктурном комплексе $(\mathrm{ET})_{4} \mathrm{HgBr}_{4}\left(\mathrm{C}_{6} \mathrm{H}_{4} \mathrm{Cl}_{2}\right)$ [6], это единственное серьезное количественное отличие электронных систем BETS- и ЕТ-комплексов. По всей вероятности, этот факт вызван существенным 
ослаблением электрон-фононного взаимодействия в BETS-металле. Такое ослабление неоднократно фиксировалось в традиционных BETS-комплексах (см., например, [13]). Его причина до сих пор не до конца ясна.

Таким образом, установлено, что в двухслойном органическом металле (BETS $)_{4} \mathrm{HgBr}_{4}\left(\mathrm{C}_{6} \mathrm{H}_{4} \mathrm{Cl}_{2}\right)$ :

1) межслоевой зарядовый перенос осуществляется в некогерентном режиме, что соответствует системе почти невзаимодействующих металлических слоев;

2) спектр осцилляций ШдГ хорошо согласуется с теоретическими расчетами зонной структуры и экспериментальными результатами, полученными для изоструктурного комплекса $(\mathrm{ET})_{4} \mathrm{HgBr}_{4}\left(\mathrm{C}_{6} \mathrm{H}_{4} \mathrm{Cl}_{2}\right)$;

3) замещение части атомов серы атомами селена в катионном слое не приводит к существенным изменениям электронной структуры;

4) значительное уменьшение величин циклотронных масс в исследованном материале, скорее всего, связано с ослаблением электрон-фононного взаимодействия в нем.

Работа выполнена по теме государственного задания, номер госрегистрации 0089-2019-0011 (синтез образцов и измерения в отсутствие магнитного поля) и в рамках проекта РФФИ № 18-02-00308 (исследования в магнитном поле).

\section{Список литературы}

[1] Kartsovnik M.V. // Chem. Rev. 2004. V. 104. P. 5737-5781.

[2] Saito G., Yoshida Y. // Bull. Chem. Soc. Jpn. 2007. V. 80. P. 1-137.

[3] Kartsovnik M.V. // The physics of organic conductors and superconductors / Ed. A. Lebed. Berlin-Heidelberg: Springer, 2008. Р. 185-247.

[4] Прохорова Т.Г., Ягубский Э.Б. // Успехи химии. 2017. Т. 86. B. 2. P. $164-180$.

[5] Lyubovskaya R., Zhilyaeva E., Shilov G., Audouard A., Vignolles D., Canadell E., Pesotskii S., Lyubovskii R. // Eur. J. Inorg. Chem. 2014. N 24. P. 3820-3836.

[6] Любовский Р.Б., Песочкий С.И., Шилов Г.В., Жиляева Е.И., Флакина А.М., Любовская Р.Н. // ЖЭТФ. 2016. T. 150 . B. 2. C. $368-371$.

[7] Moses P., McKenzie R.H. // Phys. Rev. B. 1999. V. 60. P. 7998-8011.

[8] Gutman D.B., Maslov D.L. // Phys. Rev. B. 2008. V. 77. P. 035115.

[9] Grigoriev A.D., Grigoriev P.D. // Low Temp. Phys. 2014. V. 40. P. 367-370.

[10] Stark R.W., Friedberg C.V. // J. Low. Temp. Phys. 1974. V. 1. P. 111-146.

[11] Kaganov M.I., Slutskin A.A. // Phys. Rep. 1983. V. 98. P. 189211.

[12] Kartsovnik M.V., Logvenov G.Yu., Ishiguro T., Biberacher W., Anzai H., Kushch N.D. // Phys. Rev. Lett. 1996. V. 77. P. 2530-2533.

[13] Песочкий С.И., Любовский Р.Б., Карцовник М.В., Биберахер В., Кущ, Н.Д., Кобаяши А., Чжсоу Б. // ЖЭТФ. 2009. T. 136. B. 4. C. 771-774. 